\title{
Editorial: Advances in the Biology and Conservation of Marine Turtles
}

\author{
Sara M. Maxwell ${ }^{1,2 *}$, Annette C. Broderick ${ }^{3}$, Peter H. Dutton ${ }^{4}$, Sabrina Fossette-Halot ${ }^{5}$, \\ Mariana M. P. B. Fuentes ${ }^{6}$ and Richard D. Reina ${ }^{7}$ \\ ${ }^{1}$ School of Interdisciplinary Arts and Sciences, University of Washington Bothell, Bothell, WA, United States, ${ }^{2}$ Department of \\ Biological Sciences, Old Dominion University, Norfolk, VA, United States, ${ }^{3}$ Centre for Ecology and Conservation, University of \\ Exeter, Penryn, United Kingdom, ${ }^{4}$ NOAA Fisheries, Southwest Fisheries Science Center, La Jolla, CA, United States, ${ }^{5}$ Marine \\ Science Program, Department of Biodiversity, Conservation and Attractions, Kensington, WA, Australia, ${ }^{6}$ Marine Turtle \\ Research, Ecology and Conservation Group, Department of Earth, Ocean, and Atmospheric Science, Florida State \\ University, Tallahassee, FL, United States, ${ }^{7}$ School of Biological Sciences, Monash University, Clayton, VIC, Australia
}

Keywords: marine protected area, satellite tracking, genetics, stable isotopes, bycatch, ocean noise, population demographics, social pressure

\section{OPEN ACCESS}

Edited by:

Graeme Clive Hays,

Deakin University, Australia

Reviewed by:

Frontiers in Marine Science Editorial Office,

Frontiers Media SA, Switzerland

*Correspondence: Sara M. Maxwell smmax@uw.edu

Specialty section:

This article was submitted to Marine Conservation and Sustainability, a section of the journal Frontiers in Marine Science

Received: 19 September 2018 Accepted: 11 January 2019

Published: 31 January 2019

Citation:

Maxwell SM, Broderick AC Dutton PH, Fossette-Halot S, Fuentes MMPB and Reina RD (2019) Editorial: Advances in the Biology and Conservation of Marine Turtles.

Front. Mar. Sci. 6:9.

doi: 10.3389/fmars.2019.00009

\section{Editorial on the Research Topic}

\section{Advances in the Biology and Conservation of Marine Turtles}

Marine turtles have been the subject of research over many decades, inspired by their unique life history and necessitated by their declining populations from a suite of human impacts including direct harvest, bycatch in marine fisheries, pollution, and climate change. Despite this, much about marine turtle biology has remained a mystery (Godley et al., 2008; Rees et al., 2016; Wildermann et al., 2018), but the rate of scientific discovery is increasing rapidly. As research techniques and conservation practices expand, the marine turtle research community has kept abreast of these developments and their application to marine turtles. In this special Research Topic, researchers submitted articles related to cutting-edge work in biology and conservation. The resulting 10 articles bring new insights across marine turtle movement, conservation, and methodological and analytical techniques, as well as other understudied areas and issues.

\section{MARINE TURTLE MOVEMENT AND CONSERVATION}

Contributing researchers filled critical knowledge gaps on movement of marine turtles across life history stages and sexes. Bond and James revealed the pre-nesting and mating movements and habitats of both male and female leatherback marine turtles (Dermochelys coriacea) in the North Atlantic Ocean. They identified both the timing and potential location of leatherback mating areas in coastal waters adjacent to nesting beaches and characterized a relatively confined geographic area likely used by both males and females to forage before the nesting season.

Dawson et al. used satellite tracking to reveal critical habitat for internesting olive ridleys (Lepidochelys olivacea) from a key nesting site located adjacent to an estuary heavily-used for shipping, fishing and other human activities. Diving data indicated that bottom-based fisheries were likely to pose significant threats as turtles rested on the estuarine bottom between nesting 
bouts, and satellite tracking data was used to design a marine protected area in the region to protect turtles during this important life-history stage.

Finally, Robson et al. developed a method to determine where and when to release rehabilitated turtles in relation to currents and ocean features to give turtles the greatest chance of encountering suitable habitat for survival. Using Western Australia as a case-study, the authors found a region along the northwest coast that was most conducive to release, as turtles would be quickly transported to deep, offshore waters for most of the year. Given the extensive resources put into rehabilitation-particularly of marine turtle species or populations-such information is critical for the success of rehabilitation efforts.

\section{METHODOLOGICAL AND ANALYTICAL TECHNIQUES}

Contributors to this topic explored new analytical techniques or new applications of existing techniques to better understand the biology of marine turtles, and thus improve conservation and management practices. Komoroske et al. conducted a thorough review of how genetic techniques have advanced our understanding of marine turtle population boundaries and connectivity, evolutionary history, phytogeography, life history, population vital rates, and human threats to marine turtles. Each of these aspects has the potential to contribute to the conservation of marine turtles. For example, increased resolution of genetic markers allowing differentiation between populations has been critical for defining population units to conserve, and genetic fingerprinting has been used as a tagging tool and to census the number of breeding males (Komoroske et al.). Additionally, transcriptomics and epigenetic markers help us understand responses to environmental perturbations such as rising nesting beach temperatures and environmental pollutants, and further highlight the heritability of such genetic responses (Gomez-Picos et al., 2014; Tedeschi et al., 2016).

Stable isotopes have become a useful technique to understand the biogeography and foraging habits of marine species, and Peavey et al. applied both bulk and compound specific stable isotope techniques to describe the generalist nature of olive ridley marine turtles in the Pacific Ocean. They demonstrated that plasticity in their foraging strategy has likely allowed increased populations despite the susceptibility of arribadas to be impacted by humans (Plotkin et al., 2012).

Finally Hoover et al. considered attachment techniques of transmitters to both hard- and soft-shelled marine turtle species. With increased hatchling tracking to better understand the "lost years," it is important to understand the potential impacts of transmitter attachment on small individuals. They demonstrated the efficacy of a new Velcro attachment of acoustic tags for tracking hatchling movement that avoids some of the negative impacts of harnesses.

\section{INSIGHTS INTO UNDERSTUDIED AREAS AND ISSUES}

Examples of emerging issues in sea turtle conservation biology include the impacts of ocean noise on marine turtle behavior and basic knowledge on the population demographics in understudied regions of their range. Summers et al. provided demographic information on a data-limited but endangered population of green turtles in the Northern Mariana Islands. Poaching contributed to reduced population growth and a female bias is suspected due to elevated nest temperatures. They also found lower population growth rates than expected, highlighting the need for continued conservation efforts in this region.

Anthropogenic noise is a major concern in the marine environment but understanding of impacts on marine turtles is limited. Tyson et al. used a novel sound-recording device to determine ambient noise and turtles behavioral responses. Using a three-axis accelerometer, gyroscope, and magnetometer to record the turtle's pitch, roll, and heading, behavior was determined in response to noise; in this case a green turtle responded to boat traffic by sitting on the seafloor bottom until the boat had passed. This is a major advance in understanding the ambient environment experienced by turtles-and the potential impacts of ocean noise.

Bycatch reduction techniques have been influential in reducing incidental capture of turtles in many fisheries, but basin-wide analyses are rarely conducted. Swimmer et al. compared bycatch rates in the longline fisheries in both the Atlantic and Pacific before and after the application of regulations and bycatch technologies and found that circle hooks and squid bait (instead of fish) were the most broadly successful techniques, reducing bycatch by between 40 and 95\% across loggerhead and leatherback turtles. Other factors (i.e., light sticks, sea surface temperature) influenced bycatch rates in specific areas. This basin-wide insight is critical for development and support of bycatch reduction techniques.

Finally, Alexander et al. moved beyond traditional conservation techniques such as laws and economic incentives to explore the use of taboos and social pressure to increase turtle conservation in Ghana and beyond. Marine turtles have important cultural and spiritual connections in many Ghanian communities; as a result, Alexander et al. highlighted that in several communities, turtles are not targeted and are frequently released when caught incidentally. Social pressures can therefore be a key way to leverage conservation in many societies.

Collectively the studies in this Special Topic significantly advance our understanding of the current issues and solutions in marine turtle biology and conservation.

\section{AUTHOR CONTRIBUTIONS}

All authors listed have made a substantial, direct and intellectual contribution to the work, and approved it for publication. 


\section{REFERENCES}

Godley, B., Blumenthal, J., Broderick, A., Coyne, M., Godfrey, M., Hawkes, L., et al. (2008). Satellite tracking of sea turtles: where have we been and where do we go next? Endang. Species Res. 4, 3-22. doi: 10.3354/esr00060

Gomez-Picos, P., Sifuentes-Romero, I., Merchant-Larios, H., Hernandez-Cornejo, R., Diaz-Hernandez, V., and Garcia-Gasca, A. (2014). Expression of aromatase in the embryonic brain of the olive ridley sea turtle (Lepidochelys olivacea), and the effect of bisphenol-A in sexually differentiated embryos. Int. J. Dev. Biol. 58, 733-741. doi: 10.1387/ijdb.140192ag

Plotkin, P. T., Brise-o-Due-as, R., and Abreu-Grobois, F. A. (2012). "Interpreting signs of olive ridley recovery in the Eastern Pacific," in Sea Turtles of the Eastern Pacific: Advances in Research and Conservation, eds J. A. Seminoff and B. P. Wallace (Tuzscon, AZ: The University of Arizona Press), 302-335.

Rees, A., Alfaro-Shigueto, J., Barata, P., Bjorndal, K., Bolten, A., Bourjea, J., et al. (2016). Are we working towards global research priorities for management and conservation of sea turtles? Endang. Species Res. 31, 337-382. doi: $10.3354 /$ esr00801

Tedeschi, J. N., Kennington, W. J., Tomkins, J. L., Berry, O., Whiting, S. D., Meekan, M. G., et al. (2016). Heritable variation in heat shock gene expression: a potential mechanism for adaptation to thermal stress in embryos of sea turtles. Proc. R. Soc. B Biol. Sci. 283:20152320. doi: 10.1098/rspb. 2015.2320

Wildermann, N. E., Gredzens, C., Avens, L., Barrios-Garrido, H. A., Bell, I., Blumenthal, J., et al. (2018). Informing research priorities for immature sea turtles through expert elicitation. Endang. Species Res. 37, 55-76. doi: 10.3354 /esr00916

Conflict of Interest Statement: The authors declare that the research was conducted in the absence of any commercial or financial relationships that could be construed as a potential conflict of interest.

Copyright (c) 2019 Maxwell, Broderick, Dutton, Fossette-Halot, Fuentes and Reina. This is an open-access article distributed under the terms of the Creative Commons Attribution License (CC BY). The use, distribution or reproduction in other forums is permitted, provided the original author(s) and the copyright owner(s) are credited and that the original publication in this journal is cited, in accordance with accepted academic practice. No use, distribution or reproduction is permitted which does not comply with these terms. 